\title{
Diálogo, contextualização do saber e autonomia em Paulo Freire e a semipresencialidade na Educação Superior
}

\author{
Dialogue, knowledge contextualization and autonomy of \\ Paulo Freire and blended disciplines in Higher Education
}

Dialogo, contextualización del conocimiento y autonomía en Paulo Freire y la semipresencialidad en la Educación Superior

Julio Cesar Godoy Bertolin (ida

RAFAELA BOHRZ

\section{Resumo}

Ao idealizar a libertação dos indivíduos das amarras da opressão do ensino tradicional, a educação problematizadora de Paulo Freire propõe o ato pedagógico ancorado no tripé educador-educando-objeto do conhecimento, no qual o educador não é mais visto apenas como o mediador dos saberes, uma vez que o objeto de conhecimento é transformado pelo educando. Desse modo, educadores e educandos são sujeitos estratégicos do processo educacional, que buscam por meio do diálogo, da reflexão e da inserção crítica da realidade a transformação do seu contexto, tornando, assim, a educação um processo permanente e emancipatório. Nesse sentido, tais saberes da pedagogia freireana tornam-se necessários na Educação a Distância a fim de que nela se possa também produzir uma educação libertadora. Com base nesses princípios teóricos e metodológicos de educação, esta pesquisa investiga a presença das evidências freireanas referentes ao diálogo, à autonomia e à contextualização do saber nas práticas educacionais de disciplinas semipresenciais em uma instituição de ensino superior. A fim de atender a esse objetivo, realizou-se uma revisão de literatura, relacionada à teoria de Freire e a Educação a Distância; a seleção da amostra; a aplicação de instrumentos para identificação das categorias freireanas em disciplinas semipresenciais, do tipo de observação sistemática/não participante, os quais permitem a abordagem dos conceitos nas atividades coletivas e individuais da

\footnotetext{
a Universidade de Passo Fundo (UPF), Passo Fundo, RS, Brasil. Doutor em Educação, e-mail: julio@upf.br

b Universidade de Passo Fundo (UPF), Passo Fundo, RS, Brasil. Mestra em Educação, e-mail: rafaelabohrz@upf.br
} 
plataforma Moodle; e a análise das evidências encontradas a fim de que se possa averiguar a importância da teoria freireana para a compreensão e a prática bemsucedida da EaD. Apesar de evidenciar os conceitos freireanos na semipresencialidade, este trabalho permitiu observar algumas dificuldades em relação à escolha e ao desenvolvimento das atividades propostas pelos docentes, participantes da amostra, do que se conclui que a concretização do diálogo, da autonomia e da contextualização do saber nas práticas educacionais não ocorreu de forma plena e que a modificação do ensino presencial, por meio do uso da modalidade semipresencial e das Tecnologias da Informação e Comunicação, exige um novo olhar, planejamento e inovação dos sujeitos envolvidos no processo educacional.

Palavras-chave: Diálogo. Autonomia. Contextualização do saber. Educação a Distância. Semipresencialidade.

\section{Abstract}

In designing the individuals' liberation by moorings oppression in traditional education, the education for critical consciousness, by Freire, propose a pedagogical act anchored in teacher-learners-object of knowledge, which a teacher is rarely seen as knowledge mediator, because the object of knowledge is transformed by student. Thus, teachers and learners are strategic subjects in the educational process, who search through dialogue, reflection and critical insertion in the reality, a transformation of your context, rendering, accordingly, the education into a permanent and emancipatory process. In this sense, such knowledges about Freire's pedagogy become necessary in Distance Learning in order that it can also produce an education for freedom. On the basis of these theoretical and methodological principles for education, this research investigates the presence of Freire's evidences referring to dialogue, autonomy and knowledge contextualization in educational practices of blended disciplines in one Higher Education institution. With the purpose to answer this goal, was performed a literature review related of Freire theory and Distance Learning; a selection of sample; an application of instruments to identify Freire's categories on blended disciplines, systematic observation/non-participation, which allow the conceptual approach in collective and individual activities in Moodle platform, and an analysis of founded evidences so that ascertain the significance of Freire's theory in comprehension and successful experiences in Distance Learning. While emphasizing Freire's concepts of blended disciplines, this research showed some difficulties in relation to choice and development activity by teachers, participants in the sample, than report that dialogue implementation, autonomy and knowledge contextualization in educational practices did not occur in full form and the modification of traditional education, using blended learning and Information and Communication Technology, requires a new perspective, planning and subject innovation involved in education process.

Keywords: Dialogue. Autonomy. Knowledge contextualization. Distance Learning. Blended disciplines.

\section{Resumen}

Al idealizar la liberación de los individuos de los lazos de opresión de la educación tradicional, la problemática educativa de Paulo Freire propone el acto pedagógico anclado en el trípode educador-educador-objeto del conocimiento, en el que el 
educador ya no es visto sólo como el mediador del conocimiento, ya que el objeto del conocimiento es transformado por el educador. De esta manera, los educadores y educandos son sujetos estratégicos del proceso educativo, que buscan a través del diálogo, la reflexión y la inserción crítica de la realidad la transformación de su contexto, haciendo de la educación un proceso permanente y emancipador. En este sentido, este conocimiento de la pedagogía freireana se hace necesario en la educación a distancia para que también pueda producir una educación liberadora. Con base en estos principios teóricos y metodológicos de la educación, esta investigación investiga la presencia de evidencias freireanas sobre el diálogo, la autonomía y la contextualización del conocimiento en las prácticas educativas de las disciplinas semipresenciales en una institución de educación superior. Para cumplir este objetivo, se realizó una primera revisión de la literatura relacionada con la teoría de Freire y la Educación a Distancia; la selección de muestra; la aplicación de instrumentos para la identificación de categorías freireanas en disciplinas semi-presenciales, del tipo de observación sistemática/no participante, que permiten el acercamiento conceptos en las actividades colectivas e individuales de la plataforma Moodle; y el análisis de la evidencia encontrada para determinar la importancia de la teoría freireana para la comprensión y la práctica exitosa de la educación a distancia. A pesar de destacar los conceptos freireanos en la semipresencialidad, este trabajo permitió observar algunas dificultades en relación con la elección y el desarrollo de las actividades propuestas por los profesores, participantes de la muestra, de las cuales se concluye que el logro del diálogo, la autonomía y la contextualización del conocimiento en las prácticas educativas no se produjo en su totalidad y que la modificación de la enseñanza presencial, a través del uso de la modalidad semipresencial y de las Tecnologías de la Información y la Comunicación, requiere una nueva mirada, planificación e innovación de los sujetos implicados en el proceso educativo.

Palabras clave: Diálogo. Autonomía. Contextualización del conocimiento. Educación a distancia. Semipresencialidad.

\section{Introdução}

O modo pelo qual se compreende o diálogo entre os sujeitos distintos e envolvidos na Educação a Distância (EAD) é primordial para a aprendizagem dialógica formativa em um ambiente virtual de aprendizagem e para o aprimoramento deste processo educacional.

Nesta perspectiva, Bohrz (2017) constata a necessidade de ponderação em relação ao papel e à formação contínua dos docentes, bem como a compreensão das tendências educacionais que permitem aos educandos novas oportunidades a fim de que eles possam modificar o seu mundo. Frente a isso, surge a pedagogia progressista, manifestada em três tendências: a libertária, a crítico-social dos 
conteúdos e a libertadora, pedagogia de Paulo Freire, inspirada em autores como Mounier, G. Marcel, Jasper (SAVIANI, 2008).

De acordo com Freire, as concepções metodológicas visam o diálogo, a autonomia e o apreço aos saberes dos educandos; entre outros conhecimentos condizentes à educação libertadora. Logo, o autor propõe que o ato pedagógico seja ancorado no diálogo e, especialmente, no tripé educador-educando-objeto do conhecimento. Em razão disso, o educador não é mais visto como o mediador do conhecimento, uma vez que esse é transformado pelo próprio educando. Então, é visto como significado por sujeitos cognoscentes, sendo uma leitura consciente do mundo e de suas relações naturais e sociais. Consequentemente a isso, educadores e educandos são sujeitos estratégicos do processo educacional que buscam, por meio do diálogo, da reflexão, a transformação da realidade.

Entretanto, para que isso aconteça, espera-se que o ato pedagógico envolva indivíduos problematizadores e libertadores na construção coletiva do conhecimento e na busca do conteúdo programático, não se reduzindo, portanto, à condição de objeto um do outro. Logo, a partir do diálogo, enfatiza-se o caráter histórico do homem associado à prática social, às transformações necessárias às práticas educativas e pedagógicas, as quais tornam a educação um processo permanente e emancipatório.

Ao se pensar nas práticas educativas, é necessário também ter em vista o cenário da EaD como uma saída para suprir a demanda por formação superior no país. Neste sentido, o acesso de estudantes no país que não conseguem ser atendidos pelos meios tradicionais de ensino cresce de forma acelerada. De acordo com os dados do Censo da Educação Superior divulgados pelo Instituto Nacional de Estudos e Pesquisas Educacionais Anísio Teixeira (Inep) em 2015, os números na $\mathrm{EaD}$ continuam avançando, uma vez que naquele ano atingiram 1.393 .752 de alunos matriculados. Tal evolução se deve à familiarização dos discentes com TICs, à facilidade de compartilhamento de conhecimento pela internet, às mensalidades mais acessíveis, aos horários flexíveis e à possibilidade de estudar em qualquer lugar. 
Dentro deste contexto educacional, a modalidade semipresencial ${ }^{1}$ é também vista como uma proposta em expansão nas instituições de ensino superior, uma vez que essas poderão introduzir a oferta de carga horária na modalidade de EaD na organização pedagógica e curricular de seus cursos de graduação presenciais, até o limite de $40 \%$ da carga horária total do curso. Esta tendência educacional é percebida na instituição estudada nesta pesquisa como um meio de flexibilização curricular, que possibilita novas formas de fazer pedagógico a partir de três modelos distintos de encontros e percentuais de aulas a distância - modelos A (20\%), B (50\%) e C (80\%) - que devem observados pelos coordenadores de cursos.

Nesse sentido, a observância dos saberes da pedagogia freireana torna-se necessária nas políticas educacionais desta modalidade de ensino, conforme apontado nos estudos de Silva e Claro (2007), Mafra (2007), Lopes (2014) e Vallin (2014), a fim de que nela se possa também produzir uma educação de qualidade e libertadora, tendo em vista os avanços exponenciais na expansão e oferta da modalidade no ensino superior no país. Assim, a investigação ora proposta se justifica por revisar os estudos de Paulo Freire através da análise das atividades e recursos disponibilizados aos alunos virtuais no ambiente virtual Moodle, visando, assim, a averiguação das evidências freireanas nas práticas educacionais da semipresencialidade.

Diante disso, apresentam-se os princípios elencados para esta pesquisa: inicialmente, o diálogo, visto que através disso é possível transformar o mundo, impulsionando, assim, a criticidade-problematizadora em relação às condições da comunidade e a receptividade entre educadores e educandos; posteriormente, elenca-se a autonomia que se caracteriza como um ponto de equilíbrio entre a autoridade e a liberdade, consistindo naquilo que é vivenciado no contexto social e nas experiências dos alunos, e, por fim, a contextualização do saber, gerada a partir das práticas sociais, das leituras de mundo e das curiosidades dos discentes.

Para a elaboração da metodologia, esta pesquisa se caracterizará de natureza qualitativa, uma vez que terá o ambiente virtual como fonte direta dos dados; quanto aos procedimentos técnicos, optou-se pela pesquisa bibliográfica e

\footnotetext{
${ }^{1}$ Portaria no 2.117, de 6 de dezembro de 2019.
} 
documental sobre Paulo Freire e a Educação a Distância e, enfim, os pontos de convergência da teoria de Freire e a EaD. Para a amostra foram selecionadas quatro disciplinas de cursos distintos, com diferentes números de créditos e tipos de tarefas desenvolvidas, as quais foram analisadas através da aplicação de três instrumentos distintos, que permitem a identificação, ou não, das evidências freireanas em atividades coletivas - Fórum, Wiki, Glossário, Base de Dados e Webconferência/Chat — e individuais - Tarefa, Questionário, Wiki — do ambiente virtual Moodle propostas pelos docentes.

\section{A concepção problematizadora e pedagógica freireana}

Freire defende a concepção problematizadora que se funda na criatividade, na reflexão crítica e no diálogo, centrando seus pressupostos na inserção crítica dos sujeitos na realidade, libertando-os das amarras da opressão. A partir da tomada de consciência entre o sujeito e o mundo, esta educação possibilitará a construção de novas formas de conhecimento, a formação de sujeitos ativos, críticos, curiosos e não domesticados, os quais se descobrem como sujeitos ativos e interacionais na sua própria história e sociedade, dignos do alcance de sua libertação. Nesse sentido, Borges (2013) relaciona o ato de educar entendido como atitude ética à redescoberta do sujeito histórico, livre e autônomo. Evidenciam-se, assim, conceitos, os quais significam o fenômeno educativo problematizador. No contexto da presente pesquisa, optou-se pela escolha dos eixos: diálogo, autonomia e contextualização do saber. Tal conjunto possibilita a ação educativa mais ampla, humana e transformadora dentro e fora de sala.

Em relação ao primeiro eixo, Bohrz (2017, p. 3) afirma:

ao enfocar o diálogo como um dos aspectos centrais da educação problematizadora, o conceito de dialogicidade em Freire simboliza uma visão teórico-filosófica e do processo dialético-problematizador. Para Freire (2014) a palavra verdadeira possibilita a açãoreflexão e, consequentemente, a transformação do mundo.

Neste encontro dialógico a palavra, verdadeira, é capaz de transformar o mundo, ou seja, por meio dela é possível modificar, juntamente com a ação-reflexão, 
os processos educacionais e a tarefa essencial do educador que é, segundo Freire (1967, p. 4), “a de coordenar, jamais influir ou impor”. É abrir-se à realidade dos educandos que estão envoltos em sala de aula e nas atividades pedagógicas, garantindo-lhes direito à fala em uma relação de mútuo respeito; é provocar o enriquecimento dos interlocutores, por meio do respeito pelas ideias dos outros e de valorização das mesmas.

O segundo saber necessário ao ato educativo problematizador é a autonomia que, de acordo com Freire (2013, p. 58), funda-se "na inconclusão do ser que se sabe inconcluso". É por meio dela que os educandos assumem a responsabilidade de suas ações, o poder de escolha e a exposição de suas ideias, colocando-se em defesa dos seus direitos em relação aos seus pais, educadores e Estado.

Este processo de amadurecimento do próprio ser, que ocorre de forma gradual, faz com que os educadores reflitam sobre os seus valores, posto que seja necessária a coerência e a autenticidade dos saberes no compartilhamento dos conhecimentos. Por esta razão, Freire (1992, p. 43) destaca a necessidade de ponderação quanto às suas práticas educacionais, uma vez que para ele não é válido "esconder verdades, negar informações, impor princípios, castrar a liberdade do educando ou puni-la, não importa como”.

Para isso, o educador deve refletir, criticamente, se seu discurso está de acordo com o que a autonomia propõe; estar atento ao que acontece com seus alunos; não desrespeitar os saberes e a cultura dos educandos e, enfim, encontrar-se como autônomo para formar a autonomia dos alunos. Assim, ao problematizar em torno do conceito de autonomia, o educador desenvolverá a subjetividade dos educandos, possibilitando, então, formas para que os mesmos concebam suas próprias representações de mundo de acordo com seus julgamentos e atingindo o processo natural de humanização e libertação.

O último conceito a ser observado é a contextualização do saber, a qual, na educação problematizadora, decorre por meio da compreensão do mundo e da realidade que cerca os educandos. Assim, Freire (2011, p. 30) afirma que o saber começa

Com a consciência do saber pouco (enquanto alguém atua). Pois sabendo que sabe pouco que uma pessoa se prepara para saber mais. Se tivéssemos um saber absoluto, 
já não poderíamos continuar sabendo, pois que este seria um saber que não estaria sendo. Quem tudo soubesse já não poderia saber, pois não indagaria. O homem, como um ser histórico, inserido num permanente movimento de procura, faz e refaz constantemente o seu saber. E é por isto que todo saber novo se gera num saber que passou a ser velho, o qual, anteriormente, gerando-se num outro saber que também se tornará velho, se havia instalado como saber novo.

Além disso, Freire (2014, p. 81) reconhece que: "só existe saber na invenção, na reinvenção, na busca inquieta, impaciente, permanente, que os homens fazem no mundo, com o mundo e com os outros".

Estas reinvenção e transformação constantes do saber também devem ser implementadas no processo de aprendizagem dos educandos, uma vez que eles, conforme Freire (2013, p. 28), "vão se transformando em reais sujeitos da construção e da reconstrução do saber ensinado, ao lado do educador, igualmente sujeito do processo".

Adiante da necessidade de estímulo à construção do conhecimento no educando, é preciso também valorizar os saberes já contextualizados por eles. Nesta perspectiva, Freire (2013, p. 120) também sustenta que respeitar os saberes é

A maneira correta que tem o educador de, com o educando e não sobre ele, tentar a superação de uma maneira mais ingênua por outra mais crítica de inteligir o mundo. Respeitar a leitura de mundo do educando significa tomá-la como ponto de partida para a compreensão do papel da curiosidade, de modo geral, e da humana, de modo especial, como um dos impulsos fundantes da produção do conhecimento. É preciso que, ao respeitar a leitura do mundo do educando para ir mais além dela, o educador deixe claro que a curiosidade fundamental à inteligibilidade do mundo é histórica e se dá na história, se aperfeiçoa, muda qualitativamente, se faz metodicamente rigorosa. $\mathrm{E}$ a curiosidade assim metodicamente rigorizada faz achados cada vez mais exatos. No fundo, o educador que respeita a leitura de mundo do educando, reconhece a historicidade do saber, o caráter histórico da curiosidade, desta forma, recusando a arrogância cientificista, assume a humildade crítica, própria da posição verdadeiramente científica.

O respeito aos saberes do educando exige, enfim, que o educador consiga reconhecer os conhecimentos prévios dos alunos e provocar nos mesmos o pensamento de sua história social como a experiência e a construção do saber, constituindo, assim, as relações desses sujeitos com mundo em transformação. Este saber demanda, portanto, a reformulação da própria ação de conhecer dos educadores. 
Em suma, verifica-se que os ideais educativos propostos na pedagogia de Freire continuam necessários no contexto da sociedade atual, tendo em vista os desafios encontrados e a necessidade da promoção de uma educação emancipatória, que oportunize o combate a todas as formas de opressão e vise, então, à transformação social e ao fortalecimento da democracia educativa.

\section{Convergência da teoria de Freire e a Educação a Distância}

Ao afirmar que o diálogo "é o encontro em que se solidarizam o refletir e o agir dos seus sujeitos endereçados ao mundo a ser transformado e humanizado" Freire (2014, p. 109) descreve a finalidade primordial do conceito em relação ao processo educacional. Este propósito também é identificado nas estratégias didáticas na Educação a Distância, uma vez que o diálogo é de suma importância nos ambientes virtuais de aprendizagem que possuem como particularidade a separação física entre professor-aluno.

Ao colocar-se em prática o diálogo na modalidade EaD, objetivam-se o engajamento do aluno, o estímulo ao senso de pertencimento ao grupo de colegas, o incentivo à aprendizagem colaborativa, entre outros. Logo, ao promover a interação entre esses indivíduos, Bohrz (2017, p.11) reconhece que ocorre

o enriquecimento dos estudos e o "pronunciamento do mundo", por meio de problematização e reflexão dos pensamentos, e o rompimento do modelo educacional baseado na transmissão de conteúdos, o qual omite o educando, comprometendo sua participação e criatividade colaborativa.

Sob esse ponto de vista, entende-se que os docentes da modalidade online necessitam prover subsídios para os educandos que permitam o diálogo pleno; logo, eles deverão alterar sua didática. Desse modo, a escolha de temas geradores ou conteúdos programáticos a serem trabalhados nas aulas virtuais precisa estar atrelada a uma postura dialógica, ou seja, necessita oportunizar a interação entre os sujeitos nas plataformas de aprendizagem. Para isso, os educadores devem ponderar a respeito da estruturação dos conteúdos, uso adequado de hipertextos, textos, vídeos, slides, indicações bibliográficas e leituras em websites, os quais proporcionem a interatividade e a manifestação dos alunos quanto ao que foi apresentado. 
Consequentemente a isso, é preciso vincular os recursos com as atividades que possibilitam as manifestações dos alunos. Os múltiplos diálogos entre os participantes podem ser oportunizados por meio do uso das ferramentas síncronas, como o chat e webconferência, bem como das assíncronas, representadas pelo fórum de discussão, portfólio, diário de bordo e ferramenta e-mail. Além dessas, é possível identificar a presença do diálogo no fórum de avisos, normalmente utilizado com cunho informacional de prazos ou motivacional, ao incentivar as trocas e a realização das atividades. Ainda, é possível a identificação deste conceito freireano por meio da utilização do quadro de notas e dos feedbacks postados nas atividades avaliadas.

Além disso, o diálogo pode ser observado fora do contexto dos recursos e atividades propostas nas plataformas virtuais. Nesse sentido, o diálogo didático, que orienta o aluno quanto a sua interação em relação ao conteúdo, também possui relevância, pois de acordo com Filatro (2008, p. 114) ele permite:

- Ativar e focar a atenção do aluno.

- Informar e reforçar os objetivos da aprendizagem.

- Manter e aumentar o interesse e a motivação do aluno.

- Apresentar a visão geral das unidades de aprendizagem e recuperar conhecimentos prévios.

- Apresentar informações, exemplos e analogias.

- Usar estratégias de aprendizagem e adequá-las ao perfil e ao desempenho do aluno.

- Monitorar o progresso do aluno e esclarecer dúvidas.

- Oferecer feedback, sugerindo leituras e atividades complementares.

- Orientar a prática, enfatizando a aplicação dos conteúdos a novas situações.

- Oferecer sínteses e revisões.

Esta forma de interação permite, portanto, a participação dos alunos na construção do conhecimento e, ainda, auxilia os educadores no processo de planejamento das disciplinas e cursos a distância.

Nesse contexto, pode-se averiguar que o diálogo se torna relevante no ponto de vista pedagógico da Educação a Distância na medida em que através dele se estabelece um processo construtivo, capaz de garantir a aprendizagem e a fundamentação do conhecimento por meio de todos os envolvidos. 
A autonomia também exerce um papel fundamental na educação problematizadora, pois, além de aguçar a curiosidade e os gostos dos educandos, a linguagem usada para sua expressão também remete a um posicionamento moral, pois, de acordo com Freire (2014, p. 58): “o respeito à autonomia e à dignidade de cada um é um imperativo ético e não um favor que podemos ou não conceder uns aos outros".

Do mesmo modo, o respeito ao educando e às coisas que se relacionam ao seu universo e, ainda, à sua moral também devem ser observados nos processos de ensino-aprendizagem na modalidade a distância, visto que neste modelo educacional o aprendizado autônomo se ressignifica ao atender às necessidades vindas dos avanços tecnológicos e se torna indispensável para o perfil dos alunos e a construção dos seus conhecimentos.

Para que consiga atingir a autonomia, o aprendiz virtual necessita de disciplina, visto que será preciso dedicar-se para as atividades e organizar seus estudos, moldando seu próprio ritmo de aprendizagem; orientar-se nas tarefas propostas, desenvolvendo, então, suas capacidades de responsabilidade, construção de conhecimento por meio dos recursos e atividades disponibilizados no AVA, entre outras. Além disso, os alunos deverão atentar-se ao seu tempo e horários de estudos, adequando-se ao cronograma de atividades. A autonomia também pode ser vislumbrada por meio de outras ações independentes, como as interações semanais nos fóruns para dialogar com os colegas que também estão participando da tarefa, a realização das atividades por conta própria, a prática das leituras indicadas sem mediação do docente, a busca por leituras complementares aos materiais didáticos disponibilizados no curso. Ou seja, compreende-se a autonomia do aluno em relação a questões técnicas, tarefa e tempo.

Entretanto, o desenvolvimento da autonomia do aluno também depende das ações dos professores e da equipe pedagógica multidisciplinar, uma vez que as mediações desses sujeitos, a escolha da metodologia e do material didático a serem disponibilizados, bem como das tecnologias que serão empregadas influenciam no despertar da curiosidade, das potencialidades e no desprendimento dos alunos virtuais dos mecanismos de passividade, edificando, assim, o seu saber. 
Desse modo, de acordo com Filatro (2008, p. 115), o desenvolvimento de recursos e atividades que promovam a autonomia pode ser proposto por meio de

Módulos de ambientação, apoio tecnológico e administrativo, manuais de estudo online, organização da interface do ambiente de aprendizagem e regras claras para interação. Aqui, o objetivo é desobrigar o educador de lidar com tarefas repetitivas [...], liberando-o para uma interação mais centrada no aluno.

Além do que foi proposto pela autora, para que a aprendizagem autônoma seja desenvolvida na $\mathrm{EaD}$ é preciso prever tarefas que possibilitem a participação em práticas sociais de investigação e aprendizagem, a disponibilização de espaços para comunicação síncrona e assíncrona entre os participantes e professores na sala de bate-papo dos AVAS e nos fóruns de discussão, a construção de portfólios, coleção de registros do que foi aprendido em aula, que pode envolver anotações e revisões de sala de aula, comentários gerais sobre a disciplina, assim como outros trabalhos representativos dos alunos.

A autonomia, portanto, é vista como um pilar de sustentação nos cursos a distância, pois por meio da aprendizagem autônoma e uso das TICs se desfocaliza o ensino passivo, e o estudante torna-se ativo e engajado no seu processo de aprendizagem e construção do conhecimento.

Por fim, no exercício da docência online, professores e tutores estão constantemente em busca de novas estratégias que simplifiquem a apropriação dos conhecimentos, os quais serão transmitidos aos alunos. Entretanto, para que ocorra a significação imediata, é necessária a associação do conteúdo com a realidade da vivência real dos discentes virtuais.

Neste sentido, é essencial que o professor reconheça seus alunos e suas experiências para que o conhecimento não seja imposto, mas sim consequência de um processo de compreensão e reflexão crítica do saber prévio. Em meio a esse entendimento, ao contextualizar o conhecimento, o aluno deixa de ser espectador passivo. Logo, conforme Freire (2013, p. 26), "nas condições de verdadeira aprendizagem os educandos vão se transformando em reais sujeitos da construção e da reconstrução do saber ensinado" e aprendem o pensar certo. 
Esta reconstrução do saber ensinado envolve, por parte dos alunos, a apropriação das compreensões já adquiridas, a aquisição de habilidades que as relacionem com seus contextos de usos, a realização de comentários consistentes e contextualizados referentes às ideias apresentadas inicialmente pelos docentes nas tarefas propostas, a sua interação com o conteúdo, articulando, assim, seus questionamentos e confrontando os mesmos com pontos de vista diferentes. Além disso, a aprendizagem situada e a contextualização do saber podem ser instigadas nas tarefas online, usando como fontes de informação os próprios colegas, pois, de acordo com Filatro (2008, p. 115), “os outros alunos também podem e devem ser consultados para a resolução de problemas reais".

Em relação aos docentes, para que a aprendizagem seja situada é necessário o replanejamento do processo educativo, logo, é imprescindível trabalhar de forma problematizada, envolvendo situações reais e particulares e o contexto do aluno.

Para que as atividades se integrem ao contexto social dos estudantes, Vallin (2014, p. 42) corrobora que é necessário que o docente da EaD promova "a interação do/a estudante com os conteúdos, articulação de questionamentos, experiências de aplicação, análise crítica, confronto com os pontos de vista de outros sujeitos em relação ao mesmo conteúdo".

Desse modo, é preciso que os docentes desenvolvam elementos que permitam ativar o conhecimento prévio do aluno, sejam eles por meio de elaboração de mapas conceituais a partir da conexão de noções já existentes junto às novas informações, construção de gráficos que mostrem a analogia entre o novo conteúdo e o antigo, elaboração de imagens que demonstrem mudanças e avanços ao longo de um determinado tempo e espaço, etc., possibilitando, assim, a entrega do conhecimento de forma problematizada.

Por meio dos conceitos apresentados visualiza-se que a formação do sujeito emancipatório, por meio do diálogo, da autonomia e da contextualização dos saberes prévios, possui elementos que estreitam os laços ideológicos entre Paulo Freire e os embasamentos teóricos que fundamentam a Educação a Distância.

Desse modo, para que a docência universitária, na modalidade a distância, desenvolva um ambiente democrático em que todos ensinem e aprendam, com saberes conectados, é necessário que as práticas educacionais sejam reestruturadas, 
tendo em vista a necessidade da troca mútua entre professor e aluno, da capacidade para tomada de decisões e da associação do conteúdo com contextos locais a fim da significação.

Assim sendo, a dinâmica educacional baseada na pedagogia colaborativa e dialógica integrada ao uso das Tecnologias da Informação e Comunicação e às ferramentas dos ambientes virtuais potencializa a docência e aprendizagem nos cursos a distância e conflui para múltiplas oportunidades de ensino/aprendizagem.

\section{Delimitação do universo pesquisado}

Este estudo teve como universo de pesquisa as disciplinas semipresenciais, ministradas no primeiro e segundo semestres de 2016, de cursos de graduação reconhecidos em uma instituição de ensino superior localizada em Passo Fundo/RS. No ano em questão, a IES autorizou para a semipresencialidade os cursos de graduação, disciplinas e indivíduos que podem ser observados na Tabela 1 abaixo.

Tabela 1 - Número de cursos, disciplinas, professores e alunos que utilizaram a semipresencialidade em 2016

\begin{tabular}{c|c|c|c|c}
\hline SEMESTRE & $\begin{array}{c}\text { CURSOS DE } \\
\text { GRADUAÇÃO/ÁREA }\end{array}$ & DISCIPLINAS & PROFESSORES & ALUNOS \\
\hline $\mathbf{2 0 1 6 / 1}$ & 43 & 67 & 83 & 1804 \\
\hline $\mathbf{2 0 1 6 / 2}$ & 42 & 72 & 87 & 1932 \\
\hline
\end{tabular}

Fonte: Os autores, 2017.

Frente a este universo de disciplinas e sujeitos envolvidos e objetivando a identificação de conceitos, optou-se pelos seguintes critérios: a) uma disciplina de cada uma das áreas a seguir: área 1, Ciências Exatas e da Terra + Engenharias; área 2, Ciências da Saúde + Ciências Biológicas + Ciências Agrárias; área 3, Ciências Sociais Aplicadas; área 4, Ciências Humanas + Linguística, Letras e Artes; b) disciplinas com 50\% de semipresencialidade; c) disciplinas ministradas no ano de 2016; e d) no desenvolvimento das disciplinas no ambiente virtual de aprendizagem, 
a escolha das ferramentas utilizadas no AVA não pode ter sido limitada ao uso de apenas um tipo de atividade.

Resultante a esta apuração, foram selecionadas quatro disciplinas de diferentes cursos, com distintos números de créditos e tipos de tarefas desenvolvidas, conforme podem ser observadas na Tabela 2.

Tabela 2 - Disciplinas semipresenciais 2016

\begin{tabular}{|c|c|c|c|c|c|c|}
\hline ÁREA 1 & SEMESTRE & CURSO & $\begin{array}{l}\text { SP } \\
(\%) \\
)\end{array}$ & $\begin{array}{l}\text { CRÉDITOS } \\
\text { PRÁTICOS }\end{array}$ & $\begin{array}{l}\text { CRÉDITOS } \\
\text { TEÓRICOS }\end{array}$ & $\begin{array}{c}\text { ÁREAS/CNP } \\
\mathbf{Q}\end{array}$ \\
\hline $\begin{array}{c}\text { Disciplina } \\
1\end{array}$ & $\begin{array}{c}2016-1^{\circ} \\
P L\end{array}$ & Computação & 50 & 0 & 2 & 1 \\
\hline ÁREA 2 & & CURSO & $\begin{array}{l}\text { SP } \\
(\%) \\
)\end{array}$ & $\begin{array}{l}\text { CRÉDITOS } \\
\text { PRÁTICOS }\end{array}$ & $\begin{array}{l}\text { CRÉDITOS } \\
\text { TEÓRICOS }\end{array}$ & $\begin{array}{c}\text { ÁREAS/CNP } \\
\mathbf{Q}\end{array}$ \\
\hline $\begin{array}{c}\text { Disciplina } \\
2\end{array}$ & $\begin{array}{c}2016-1^{0} \\
P L\end{array}$ & Nutrição & 50 & 0 & 2 & 2 \\
\hline ÁREA 3 & & CURSO & $\begin{array}{c}\text { SP } \\
(\%) \\
)\end{array}$ & $\begin{array}{l}\text { CRÉDITOS } \\
\text { PRÁTICOS }\end{array}$ & $\begin{array}{l}\text { CRÉDITOS } \\
\text { TEÓRICOS }\end{array}$ & $\begin{array}{c}\text { ÁREAS/CNP } \\
\mathbf{Q}\end{array}$ \\
\hline $\begin{array}{c}\text { Disciplina } \\
3\end{array}$ & $\begin{array}{c}2016-1^{0} \\
P L\end{array}$ & Arquitetura & 50 & 0 & 2 & 3 \\
\hline ÁREA 4 & & CURSO & $\begin{array}{l}\text { SP } \\
(\% \\
)\end{array}$ & $\begin{array}{l}\text { CRÉDITOS } \\
\text { PRÁTICOS }\end{array}$ & $\begin{array}{l}\text { CRÉDITOS } \\
\text { TEÓRICOS }\end{array}$ & $\begin{array}{c}\text { ÁREAS/CNP } \\
\mathbf{Q}\end{array}$ \\
\hline $\begin{array}{c}\text { Disciplina } \\
4\end{array}$ & $\begin{array}{c}2016-1^{\circ} \\
P L\end{array}$ & $\begin{array}{l}\text { Letras/Língua } \\
\text { Espanhola }\end{array}$ & 50 & 0 & 4 & 4 \\
\hline
\end{tabular}

Fonte: Os autores, 2017.

Tais disciplinas, ministradas no ano letivo de 2016, primeiro semestre, juntamente com os instrumentos de coletas de dados, possibilitam a observação sistemática das evidências freireanas, conforme relatada na seção seguinte.

\section{Evidências do conceito diálogo na semipresencialidade}

Para a identificação, ou não, das evidências do diálogo nas disciplinas semipresenciais da instituição investigada, foram analisadas a configuração inicial das aulas a distância, as atividades individuais e coletivas propostas pelos docentes e o uso dos recursos adicionais da plataforma Moodle. O Quadro 1 apresenta um 
apanhado das evidências do diálogo identificadas nas quatro amostras, conforme pode ser observado abaixo.

Quadro 1 - Síntese das evidências do diálogo

\begin{tabular}{|c|c|}
\hline \multicolumn{2}{|r|}{ Sequência didática } \\
\hline $\begin{array}{c}\text { Configuração } \\
\text { inicial e } \\
\text { organização } \\
\text { dos elementos }\end{array}$ & $\begin{array}{l}\text { Diálogo pode ser evidenciado, mesmo que não confirmado nas ações } \\
\text { dos estudantes das amostras, tendo em vista a oportunização dos } \\
\text { docentes quanto à apresentação da modalidade adotada e do } \\
\text { cronograma das aulas, dando êfase para as datas em que ocorreram } \\
\text { os encontros presenciais e a distância. }\end{array}$ \\
\hline \multicolumn{2}{|r|}{ Atividades Coletivas } \\
\hline Fórum & $\begin{array}{l}\checkmark \quad \text { Ausência do fórum de apresentação dos alunos e discussão } \\
\text { permanente. } \\
\checkmark \text { Esclarecimento por parte dos docentes da necessidade do confronto } \\
\text { com pontos de vista de outros participantes em relação ao mesmo } \\
\text { conteúdo. } \\
\checkmark \quad \text { Baixa interação entre estudantes nas postagens realizadas, exceto } \\
\text { quando solicitado pelo docente. } \\
\checkmark \quad \begin{array}{l}\text { Ausência de feedback, descritivo ao que o discente fez e específico ao } \\
\text { que deve ser comentado, do docente em relação às postagens feitas } \\
\text { pelos educandos. }\end{array} \\
\checkmark \quad \text { Necessidade de postagem dos feedbacks a fim de que por meio deles } \\
\text { possa-se impulsionar o diálogo crítico-problematizador. }\end{array}$ \\
\hline Wiki & $\begin{array}{l}\checkmark \text { Atividade pouco utilizada pelos docentes da amostra. } \\
\checkmark \quad \text { Enunciados das tarefas ressaltam a importância do editor colaborativo e } \\
\text { suas funcionalidades, como também a necessidade de trabalho em } \\
\text { conjunto. } \\
\checkmark \quad \text { O diálogo entre os alunos, por meio da aba Comentários, não foi } \\
\text { identificado em nenhuma das disciplinas. } \\
\checkmark \quad \text { Feedback parcial dos professores. }\end{array}$ \\
\hline Chat & $\begin{array}{l}\checkmark \quad \text { Interações realizadas nas sessões de bate-papo caracterizaram-se de } \\
\text { forma contínua, dialogando em torno das temáticas das aulas. } \\
\checkmark \quad \text { Questionamentos muito pontuais e réplicas dos alunos também } \\
\text { fidedignas aos textos sugeridos como leitura prévia. } \\
\checkmark \quad \text { Feedbacks dos docentes limitados. } \\
\checkmark \text { Falta de abertura para novos diálogos e trocas dos conhecimentos. }\end{array}$ \\
\hline \multicolumn{2}{|r|}{ Atividades Individuais } \\
\hline Tarefa & $\begin{array}{l}\checkmark \text { Presente em todas as disciplinas da amostra desta pesquisa. } \\
\checkmark \quad \text { Enunciados descritos de forma minuciosa, tendo em vista suas } \\
\text { intenções, objetivos, leituras prévias, questões a serem respondidas, a } \\
\text { formatação e extensão em que deviam ser enviados os arquivos, bem } \\
\text { como o prazo de envio das tarefas. } \\
\checkmark \quad \text { Não se constatam nas Tarefas o diálogo e a interação entre os alunos. } \\
\checkmark \quad \text { Feedback em sua maioria foram qualitativos e padronizados. } \\
\checkmark \quad \text { Recomenda-se que os professores promovam o sucesso dos discentes } \\
\text { por meio da postagem de feedback, descritivo ao que o aluno fez e } \\
\text { específico ao que deve ser comentado. }\end{array}$ \\
\hline
\end{tabular}

(Continua) 
(Conclusão)

\begin{tabular}{|c|cc|}
\hline Questionário & $\checkmark$ & $\begin{array}{l}\text { Exercícios objetivaram a revisão dos conteúdos abordados em aula. } \\
\checkmark\end{array}$ \\
& $\begin{array}{l}\text { Feedback automático, logo os alunos, ao concluírem suas tarefas, } \\
\text { visualizaram as respostas certas e erradas e o total de acertos, } \\
\text { impossibilitados, assim, do diálogo reflexivo e problematizador. } \\
\checkmark\end{array}$ & $\begin{array}{l}\text { Sugerem-se que as réplicas dos docentes foquem na facilitação da } \\
\text { comunicação e no compartilhamento de sugestões, auxiliando os } \\
\text { educandos a perceber que não estão desamparados no processo } \\
\text { educacional. }\end{array}$ \\
\hline $\begin{array}{c}\text { Envio de } \\
\text { mensagem }\end{array}$ & $\checkmark \begin{array}{l}\text { Proposto para solucionar problemas sobre a plataforma Moodle, } \\
\text { retomada dos prazos das atividades, disponibilização dos materiais no } \\
\text { AVA, liberação de notas da intranet, entre outros comunicados. }\end{array}$ \\
\hline
\end{tabular}

Fonte: Os autores, 2017.

Mediante os resultados até aqui apontados, é possível perceber que o diálogo pode ser evidenciado na configuração inicial e organização dos elementos, mesmo que não confirmado nas ações dos estudantes das amostras, tendo em vista a oportunização dos docentes quanto à apresentação da modalidade adotada e do cronograma das aulas, dando ênfase para as datas em que ocorreram os encontros presenciais e a distância, permitindo, assim, conforme Freire (2014), o encontro dos estudantes com a disciplina, o docente e os demais participantes.

Em sequência, nas atividades coletivas, verifica-se que nenhum dos docentes da amostra configurou em suas disciplinas o fórum de integração e de discussão permanente. Embora não sejam itens obrigatórios, considera-se importante suas inserções no Moodle, pois são espaços para diálogos e interações entre os participantes e os professores. Em relação ao Fórum, Wiki e Chat infere-se que essas são atividades capazes de promover e sustentar o diálogo online, facilitando, assim, a aprendizagem colaborativa.

Entretanto para que as falhas identificadas no uso destas atividades sejam superadas, é preciso que os docentes planejem, estruturem o design de suas aulas de modo a encorajar a aprendizagem interativa e a participação dos envolvidos no ambiente virtual e, além disso, é necessário que os professores promovam o sucesso dos alunos por meio da postagem de réplicas regulares, individualizadas e claras nas atividades que são disponibilizadas na plataforma.

Conclui-se que as atividades coletivas do Moodle possuem um grande potencial dialógico quando as tarefas, os conteúdos e as estratégias de avaliação são 
modelados para que ocorra a própria produção ou a sua construção do conhecimento de maneira eficaz, garantindo, assim, que os alunos se sintam como integrantes das aulas, mesmo que estas sejam virtuais, e que possuam uma postura: “dialógica, aberta, curiosa, indagadora e não apassivada” (FREIRE, 2013, p. 83).

No tocante às atividades individuais, Tarefa e Questionário, observa-se que essas não possuem potencial para promover o diálogo, uma vez que não permitem a interação entre os colegas. A única forma, neste caso, para que a interação aconteça seria por meio da postagem de feedback descritivo ao que o aluno fez e específico ao que deve ser comentado, que possibilite novas contribuições dos participantes e a reflexão crítica sobre aquilo foi estudado, auxiliando, portanto, os educandos a perceber que não estão desamparados no processo educacional.

Para que as práticas de facilitação dialógica das disciplinas semipresenciais enfatizem, de acordo com Freire, o caráter histórico do homem associado à prática social, e o diálogo se configure de forma humanizadora e transformadora, é preciso, conforme Palloff, Pratt e Rodrigues (2015, p. 35): "práticas que promovam a colaboração e a discussão entre os alunos e que os encorajem a trabalhar juntos para explorar o conteúdo do curso", promovendo, portanto a busca de material de resposta por si próprio (PALLOFF, Pratt e Rodrigues, 2013).

\section{Evidências do conceito contextualização do saber na semipresencialidade}

A fim de identificar a presença de evidências do conceito contextualização do saber, buscou-se nas disciplinas semipresenciais da instituição pesquisada a observância da interação e troca de saberes entre duas ou mais pessoas, da valorização do conhecimento do contexto e das práticas sociais dos alunos, da leitura de experiências de aplicação e análise e crítica sobre um determinado assunto. Além disso, da reconstrução e socialização dos saberes, da curiosidade e indagação do aluno em relação ao mundo, do respeito aos saberes prévios dos alunos, gerando a recordação das vivências, bem como da disposição das aulas virtuais, das atividades individuais e coletivas e do uso dos recursos adicionais da plataforma Moodle. O Quadro 2 apresenta as evidências identificadas nas amostras. 
Quadro 2 - Síntese das evidências da contextualização do saber

\begin{tabular}{|c|c|}
\hline \multicolumn{2}{|r|}{ Sequência didática } \\
\hline $\begin{array}{l}\text { Configuração } \\
\text { inicial e } \\
\text { organização } \\
\text { dos elementos }\end{array}$ & $\begin{array}{l}\text { Contextualização do saber pode ser evidenciada, mesmo que não } \\
\text { confirmada nas ações dos estudantes das amostras, tendo em vista a } \\
\text { oportunização dos docentes quanto aos saberes que os alunos } \\
\text { deveriam desenvolver até as aulas virtuais e aos conhecimentos iniciais } \\
\text { da disciplina e da modalidade semipresencial. }\end{array}$ \\
\hline \multicolumn{2}{|r|}{ Atividades Coletivas } \\
\hline Fórum & 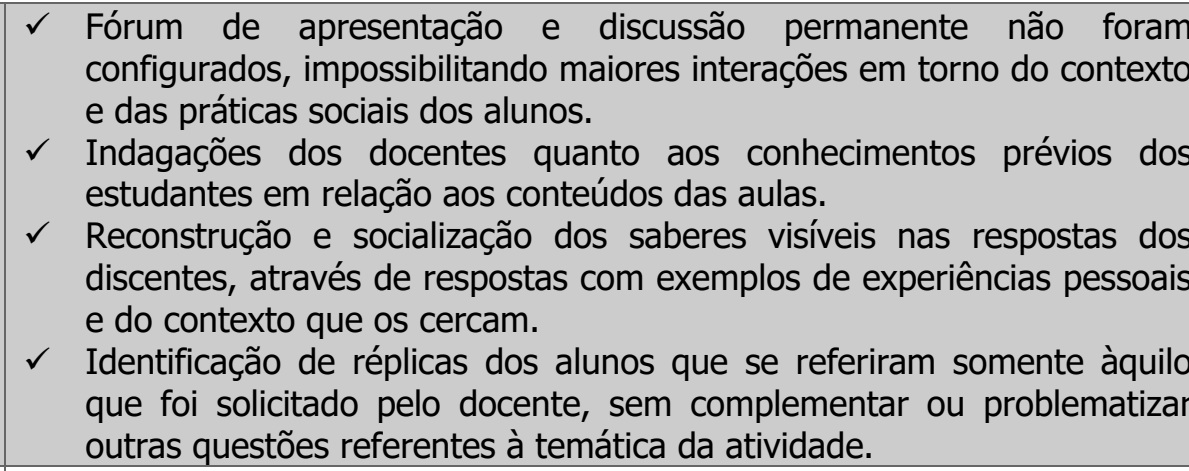 \\
\hline Wiki & 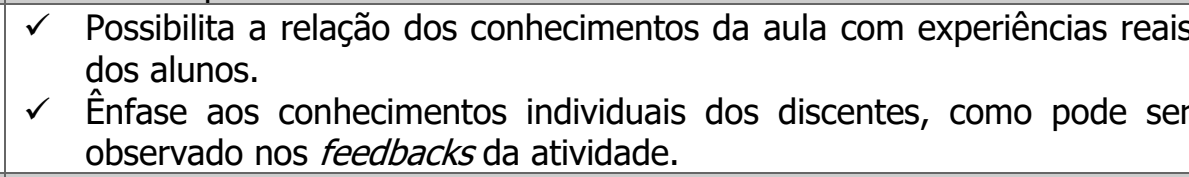 \\
\hline Chat & 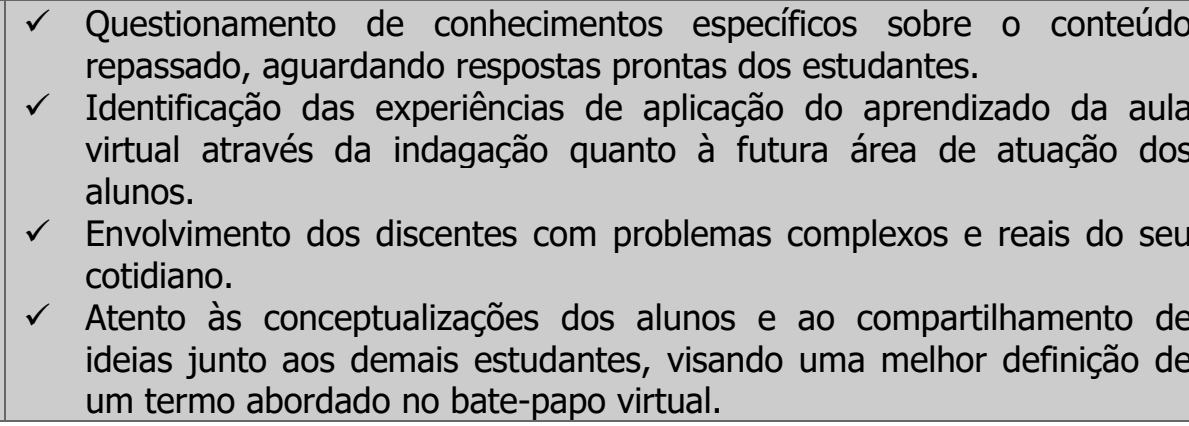 \\
\hline \multicolumn{2}{|r|}{ Atividades Individuais } \\
\hline Tarefa & $\begin{array}{ll}\checkmark & \text { Proposta de recordação daquilo que foi abordado nos filmes. } \\
\checkmark & \text { Associação das temáticas das aulas virtuais com o contexto diário dos } \\
& \text { alunos e suas vivências. } \\
\checkmark & \text { Elaboração de trabalhos com a disposição dos saberes de uma maneira } \\
& \text { diferente da usual, o texto escrito. } \\
\checkmark & \text { Destaque e compartilhamento dos melhores trabalhos dos discentes. } \\
\checkmark & \text { Réplicas com indicações de pendências nas tarefas, escritas de um } \\
& \text { modo geral a todos os estudantes. } \\
\checkmark & \text { Necessidade de feedback individualizado, que reconheça os alunos e } \\
\text { suas experiências. }\end{array}$ \\
\hline Questionário & $\begin{array}{ll}\checkmark & \text { Associação do conhecimento prévio ao novo e suas aplicações na futura } \\
\text { área de formação dos alunos. } \\
\checkmark & \text { Interrogações feitas aos discentes permeiam a temática dos textos- } \\
\text { base das aulas virtuais. } \\
\checkmark & \begin{array}{l}\text { Questionamentos de saberes específicos, com respostas prontas, o que } \\
\text { justifica o formato de múltipla escolha. }\end{array}\end{array}$ \\
\hline \multicolumn{2}{|r|}{ Recursos adicionais do AVA } \\
\hline $\begin{array}{l}\text { Envio de } \\
\text { mensagem }\end{array}$ & $\begin{array}{l}\checkmark \quad \text { Não foram identificadas evidências do conceito nas mensagens enviadas } \\
\text { via bloco Participantes. }\end{array}$ \\
\hline
\end{tabular}

Fonte: Os autores, 2017. 
Através das averiguações até aqui apontadas, infere-se que as atividades coletivas, Fórum, Wiki e Chat, são convenientes na relação entre o que se ensina e o que se aprende, bem como na produção do conhecimento ainda não existente, visto que na maioria delas foram propostas reflexões a partir do aproveito das experiências dos alunos e, segundo Freire (2013, p. 31-32), da "realidade concreta a que se deva associar a disciplina cujo conteúdo se ensina”. Constituem-se, assim, as relações desses sujeitos com o mundo em transformação.

Em relação às atividades individuais, Tarefa e Questionário, observa-se que essas permitem a recordação das vivências, das experiências e dos conhecimentos dos alunos de forma a relacioná-la com os conteúdos das aulas a distância. Entretanto, é necessário que, neste tipo de atividade, os docentes qualifiquem suas réplicas, valorizando os saberes dos seus alunos e indagando-os em relação ao mundo.

Desse modo, conclui-se que as evidências da contextualização do saber identificadas nesta seção possibilitam aos educandos o desenvolvimento de habilidades de pensamento crítico, analítico e de pesquisa, construindo, assim, seus próprios conhecimentos e significados.

\section{Evidências do conceito autonomia na semipresencialidade}

Com o intuito de investigar a presença das evidências freireanas do conceito de autonomia, buscou-se nas disciplinas da amostra a observância da interação e o engajamento dos alunos com outros colegas, do contato dos discentes com os demais sujeitos do curso, de situações nas quais se destacam a cooperação, do questionamento das próprias hipóteses dos educandos e as apresentadas pelo educador e pelos colegas. Ainda, da capacidade dos alunos de compreender fenômenos e textos e usá-los espontaneamente, da organização dos estudantes com as atividades e o desenvolvimento da consciência de que é preciso cumprir prazos, do encorajamento à busca e ao compartilhamento de material extra para resolver as questões apresentadas, da valorização da individualidade do sujeito, da cognição nas 
atividades propostas pelos docentes e, ainda, no uso dos recursos adicionais da plataforma Moodle.

Frente ao exposto até aqui, o Quadro 3 apresenta um apanhado das evidências da autonomia identificadas nas quatro amostras.

Quadro 3 - Síntese das evidências da autonomia

\begin{tabular}{|c|c|}
\hline \multicolumn{2}{|r|}{ Sequência didática } \\
\hline $\begin{array}{l}\text { Configuração } \\
\text { inicial e } \\
\text { organização } \\
\text { dos elementos }\end{array}$ & $\begin{array}{l}\checkmark \text { A autonomia pode ser evidenciada, mesmo que não confirmada nas } \\
\text { ações dos estudantes das amostras, desde a configuração inicial da } \\
\text { disciplina e o modo como são organizados os elementos em uma } \\
\text { sequência didática para a aprendizagem, tendo em vista a } \\
\text { oportunização feita pelos docentes aos alunos para que, a partir do } \\
\text { bloco de ambientação, conheçam a plataforma Moodle, leiam o plano } \\
\text { de ensino, bem como atentem ao cronograma das atividades a } \\
\text { distância. }\end{array}$ \\
\hline \multicolumn{2}{|r|}{ Atividades Coletivas } \\
\hline Fórum & $\begin{array}{l}\checkmark \quad \text { Possibilita a interação e o engajamento dos alunos com os outros } \\
\text { colegas, uma vez que é preciso ter autonomia e opinar sobre os } \\
\text { trabalhos dos demais participantes. } \\
\checkmark \quad \text { Desenvolve a capacidade de compreender fenômenos e textos e de } \\
\text { usá-los espontaneamente, tendo em vista que a necessidade de postar } \\
\text { exemplos faz com que os estudantes reflitam sobre os conhecimentos } \\
\text { adquiridos em aula. } \\
\checkmark \quad \text { Postagem de exemplos individualizados, provindos das suas vivências. } \\
\checkmark \quad \text { Promove o encorajamento à busca e ao compartilhamento de fontes } \\
\text { diversificadas e materiais extras para a discussão das questões } \\
\text { apresentadas. } \\
\checkmark \quad \text { Baixa autonomia dos discentes para replicar as postagens dos colegas, } \\
\checkmark \quad \text { quando isso não era solicitado nos enunciados das atividades. } \\
\checkmark \text { Observação e cumprimento dos prazos para postagem dos exercícios. }\end{array}$ \\
\hline Wiki & 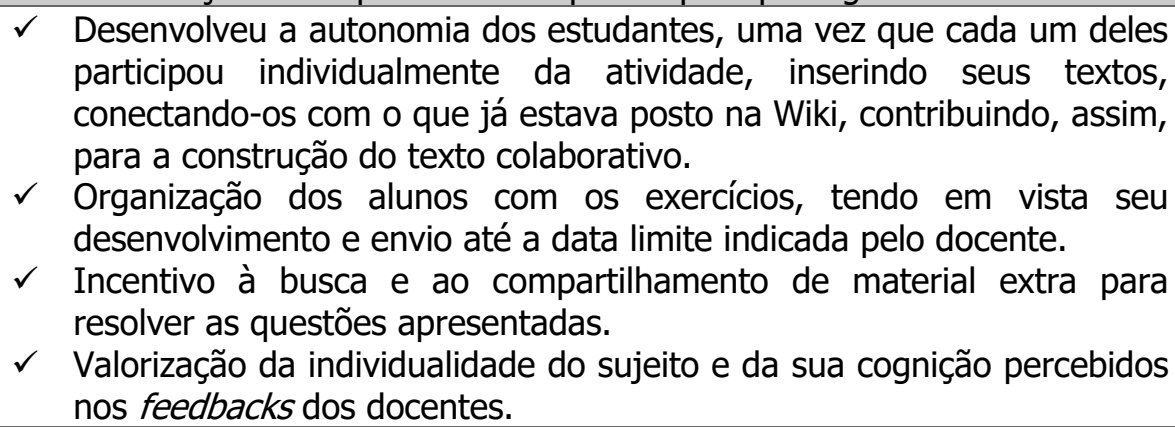 \\
\hline Chat & $\begin{array}{l}\checkmark \text { Atento dos alunos em relação à divisão dos grupos e aos horários de } \\
\text { realização das sessões de bate-papo. } \\
\checkmark \quad \text { Interação entre os sujeitos, bem como autonomia dos alunos em } \\
\text { busca de respostas para os problemas encontrados. }\end{array}$ \\
\hline & Atividades Individuais \\
\hline
\end{tabular}

(Continua) 
(Conclusão)

\begin{tabular}{|c|c|c|}
\hline Tarefa & $\checkmark$ & $\begin{array}{l}\text { Respostas foram avaliadas individualmente, de forma quanti e } \\
\text { qualitativa. }\end{array}$ \\
$\checkmark$ & $\begin{array}{l}\text { Ênfase aos melhores trabalhos elaborados pelos alunos. } \\
\text { Desenvolvimento da capacidade de compreender fenômenos e textos e } \\
\text { de usá-los espontaneamente, pois os estudantes tiveram que discutir } \\
\text { as temáticas propostas pelos docentes a partir dos seus próprios } \\
\text { pontos de vista. }\end{array}$ \\
& $\checkmark \begin{array}{l}\text { Consciência de que é preciso cumprir os prazos, visto que os alunos } \\
\text { desenvolveram as atividades até a data limite. }\end{array}$ \\
\hline Questionário & $\checkmark$ & $\begin{array}{l}\text { Valorização dos comentários/feedbacks, individualizados, quanti e } \\
\text { qualitativos, escritos nas atividades dos educandos. }\end{array}$ \\
& $\checkmark \begin{array}{l}\text { As perguntas desenvolvidas relacionavam-se aos conteúdos das } \\
\text { disciplinas e consideraram a autonomia dos alunos na escolha da } \\
\text { alternativa correta nas questões. }\end{array}$ \\
& $\checkmark \begin{array}{l}\text { Desenvolvimento da consciência de que é preciso cumprir os prazos, } \\
\text { pois os estudantes responderam as atividades até a data programada. } \\
\text { Feedback automático das atividades, os quais apenas apontavam as } \\
\text { respostas certas e erradas, totalizando a quantidade de acertos de } \\
\text { cada discente. } \\
\text { Ausência de feedbacks mais detalhados dos desempenhos dos alunos, } \\
\text { os quais respeitassem os pensamentos e comentassem as ideias } \\
\text { apresentadas e as omissões identificadas, ajudando os educandos a } \\
\text { desenvolver uma experiência reflexiva e crítica e o sentimento de que } \\
\text { foram bem-sucedidos em suas ações. }\end{array}$ \\
\hline
\end{tabular}

Fonte: Os autores, 2017.

Através dos resultados até aqui apresentados, é possível compreender que a autonomia pode ser evidenciada, mesmo que não confirmada nas ações dos estudantes das amostras, desde a configuração inicial da disciplina e o modo como são organizados os elementos em uma sequência didática para a aprendizagem, tendo em vista a oportunização feita pelos docentes aos alunos para que, a partir do bloco de ambientação, conheçam a plataforma Moodle, leiam o plano de ensino, bem como atentem ao cronograma das atividades a distância, tornando os educandos mediadores dos seus processos de aprendizagem.

Em relação às atividades coletivas, Fórum, Wiki e Chat, nota-se que essas constituem-se nas: "experiências respeitosas da liberdade" (FREIRE, 2013, p. 105), uma vez que promovem a autonomia dos alunos através da solicitação de inserção de materiais extras junto às respostas, da observância e cumprimento dos prazos para o envio das atividades, das postagens únicas de cada estudante, etc. Evidências 
essas que propiciam, acima de tudo, a liberdade de escolha e a responsabilidade na tomada de decisões quanto às soluções das atividades propostas.

Para que os docentes possam encorajar ainda mais a autonomia entre os estudantes nas atividades coletivas desenvolvidas nas disciplinas semipresenciais, sugerem-se as técnicas a seguir, indicadas por Paloff, Pratt e Rodrigues (2013, p. 137):

- Tarefas colaborativas em grupos pequenos, como as tarefas "quebra-cabeças", em que os estudantes contribuem com pedaços e, assim, compõem o todo de um tópico ou problema.

- Tarefas de pesquisa que pedem aos estudantes que procurem e apresentem recursos adicionais disponíveis na internet e em livros e revistas.

- Pedir aos estudantes que se tornem experts em um tópico dentro do escopo do curso e, então, apresentem este tópico para seus pares.

- Discussões abertas nas quais um grupo de estudantes apresenta e discute um tópico, enquanto os outros estudantes observam, registram, refletem e comentam sobre suas reflexões ao final da discussão.

Em referência às atividades individuais, Tarefa e Questionário, observa-se que essas evidenciam a autonomia, uma vez que promovem a liberdade de escolha, o incentivo à responsabilidade na tomada de decisões e permitem a organização dos alunos com as atividades, desenvolvendo, assim, a consciência de que é preciso cumprir os prazos deliberados pelos docentes. Uma das desvantagens identificadas nas atividades individuais foi a falta de um feedback mais detalhado dos desempenhos dos alunos, o qual respeitasse os pensamentos independentes e comentasse as ideias apresentadas e as omissões reconhecidas, ajudando os educandos a desenvolver uma experiência reflexiva e crítica e o sentimento de que foram bem-sucedidos em suas ações.

Por fim, para que os docentes possam incentivar ainda mais a autonomia dos estudantes nas atividades individuais, Paloff, Pratt e Rodrigues (2015, p. 147) afirma que é responsabilidade dos professores: “criar um ambiente seguro, fornecendo diretrizes e expectativas que criem uma estrutura para o curso e encorajando os estudantes a se expressar da forma como acharem apropriado no interior da estrutura”, instigando-os e concedendo-lhes poderes para que eles, enfim, se responsabilizem pelos seus processos de aprendizagem. 


\section{Considerações finais}

A partir do exposto até aqui a observância dos saberes da pedagogia freireana torna-se necessária na Educação a Distância e na semipresencialidade a fim da produção de uma educação libertadora, assim como também dialogado nos estudos de Silva e Claro (2007), Mafra (2007), Lopes (2014) e Vallin (2014). Logo, esta pesquisa demonstrou que as evidências dos conceitos de diálogo, contextualização do saber e autonomia fazem-se presentes na amostra das disciplinas semipresenciais da IES pesquisada, contribuindo para a significação da qualidade nas práticas pedagógicas e políticas educacionais, tendo em vista os avanços exponenciais na expansão e oferta da modalidade no país, bem como o alcance da meta 12, do Plano Nacional de Educação (PNE), que objetiva aumentar a escolaridade média da população a partir da elevação da taxa bruta de matrícula na Educação Superior para $50 \%$ e a taxa líquida em 33\% da população de 18 e 24 anos.

Além disso, tais evidências, problematizadas nas atividades propostas pelos docentes da amostra, ratificam o viés da humanização e transformação da Educação por meio da comunicação de experiências e trocas de saberes, da relação democrática e participativa entre professores e alunos, da mobilização pela reflexão crítica e intensificam a necessidade da ressignificação das práticas educacionais nos ambientes virtuais de aprendizagem a fim de que a educação torne-se prática imprescindível ao desenvolvimento dos sujeitos.

Esta investigação científica, apesar de apresentar as evidências freireanas na semipresencialidade, permitiu concluir que sua concretização não ocorreu de forma plena, visto que foram acentuadas algumas fragilidades em relação à escolha e ao desenvolvimento das atividades propostas pelos docentes da amostra. Frente a isso, a pesquisa permitiu o desfecho de que modificar o ensino presencial, por meio do uso da modalidade semipresencial e das Tecnologias da Informação e Comunicação, exige um novo olhar, planejamento e inovação dos sujeitos envolvidos no processo educacional. Logo, para que a semipresencialidade seja transformada e se aproxime das evidências de Freire, possibilitando a humanização e a transformação da Educação, os professores, as equipes multidisciplinares e as instituições deverão 
priorizar a Educação a Distância como uma política educacional a fim de que seja ressignificada a práxis educativa dos sujeitos inseridos nesta modalidade, superando, assim, os pontos falhos identificados neste estudo.

Além disso, para que a semipresencialidade promova uma educação de qualidade, ancorada no tripé educador-educando-objeto do conhecimento, na potencialização da mediação entre professor e alunos e no desenvolvimento do conhecimento crítico, da autonomia, da emancipação e da humanização, destaca-se a importância de que as atividades sejam configuradas de modo que os alunos possam dar ação às suas aprendizagens, preparando-os para serem bem-sucedidos nas aulas virtuais.

É fundamental, por fim, que os docentes participem das capacitações tecnológicas e profissionais, continuamente, para que possam fazer frente aos desafios da expansão da docência na modalidade a distância, possibilitando a permanência dos estudantes nos cursos, a melhoria na qualidade das ofertas e na relação entre sujeitos, bem como projetar cursos online adequados aos contextos dos alunos, nos quais se sobressaiam as evidências positivas dos conceitos de Freire, promovendo a melhoria contínua da semipresencialidade e dos perfis dos sujeitos envolvidos no processo educacional, construindo, portanto, conhecimentos renovados e um novo futuro para a educação.

\section{Referências}

BOHRZ, R. Diálogo sem distância: reflexões sobre a tutoria de um curso virtual de língua inglesa. Revista Inter Ação, v. 42, n. 2, p. 465-480, 2017.

BORGES, V. A reconstrução de uma ética pedagógica libertadora à luz de Paulo Freire. Curitiba: Editora CRV, 2013.

BRASIL. Portaria $\mathrm{n}^{\mathrm{o}}$ 2.117, de 6 de dezembro de 2019. Disponível em: http://pesquisa.in.gov.br/imprensa/jsp/visualiza/index.jsp?data $=11 / 12 / 2019$ \&jornal $=51$ 5\&pagina=131. Acesso em: 20 jan. 2020.

FILATRO, A. Design instrucional na prática. São Paulo: Pearson Education, 2008. 215 p.

FREIRE, P. Educação como Prática da Liberdade. 9. ed. Rio de Janeiro: Paz e Terra, 1967.

FREIRE, P . Extensão ou comunicação? 15. ed. Rio de Janeiro: Paz e Terra, 2011. 
FREIRE, P. Pedagogia da autonomia: saberes necessários à prática educativa. 46. ed. Rio de Janeiro: Paz e Terra, 2013.

FREIRE, P. Pedagogia da esperança: um reencontro com a pedagogia do oprimido. 7. ed. Rio de Janeiro: Paz e Terra, 1992.

FREIRE, P. Pedagogia do oprimido. Paulo Freire $-57^{\mathrm{a}}$ ed. rev. e atual. - Rio de Janeiro: Paz e Terra, 2014.

INSTITUTO NACIONAL DE ESTUDOS E PESQUISAS EDUCACIONAIS ANÍSIO TEIXEIRA (INEP). Sinopse Estatística da Educaşão Básica 2015. 2015. Disponível em: http://portal.inep.gov.br/basica-censo-escolar-sinopse-sinopse. Acesso em: 07 dez. 2016.

LOPES, A. M. As contribuições teóricas de Paulo Freire para os estudos em Educação a Distância: um estudo de caso da Rede e-Tec Brasil do CEFET-MG. 2014. 189 f. Dissertação (Mestrado em Educação Tecnológica) - Centro Federal de Educação Tecnológica de Minas Gerais, Belo Horizonte, 2014.

MAFRA, J. F. A conectividade radical como princípio e prática da educação em Paulo Freire. 2007. 262 f. Tese (Doutorado em Educação) — Universidade de São Paulo, São Paulo, 2007.

PALLOFF, R. M.; PRATT, K.; RODRIGUES, F. S. (Rev.). O instrutor online: estratégias para a excelência profissional. Porto Alegre: Penso, 2013. 198 p.

PALLOFF, R. M.; PRATT, K.; RODRIGUES, F. S. Licões da sala de aula virtual: as realidades do ensino on-line. Porto Alegre: Penso, 2015. 212 p.

SAVIANI, D. Escola e democracia. Campinas: Autores Associados, 2003.

SILVA, M.; CLARO, T. A docência online e a pedagogia da transmissão. Boletim Técnico do Senac: a revista da educaşão profissional, Rio de Janeiro, v. 33, n. 2, maio/ago. 2007. Disponível em: http://www.bts.senac.br/index.php/bts/article/view/301/284. Acesso em: 20 jul. 2016.

TODOS PELA EDUCAÇÃO (TPE). Observatório PNE. Disponível em: http://www.observatoriodopne.org.br/sobre-observatorio. Acesso em: 12 dez. 2016.

VALLIN, C. Educação a Distância e Paulo Freire. Revista Brasileira de Aprendizagem Aberta e a Distância, São Paulo, v. 13, 2014. Disponível em: http://www.abed.org.br/revistacientifica/_Brazilian/2014/02_ead_paulo_freire_pt.pdf. Acesso em: 20 jul. 2016.

RECEBIDO: $24 / 01 / 2020$

APROVADO: $18 / 05 / 2020$

RECEIVED: 01/24/2020

APPROVED: 05/18/2020

RECIBIDO: $24 / 01 / 2020$

APROBADO: $18 / 05 / 2020$ 